\section{european surgery}

ACA Acta Chirurgica Austriaca Printed in Austria

\title{
The semiotics of disease
}

\section{F. M. Riegler}

Dear Readers,

A physician takes the patient history to listen and learn. At the end of the day a diagnosis is made and implements the conduct of decisions, which lead to the therapy. Symptoms are signs, sent out by a person (Sanskrit perusha, Latin per sonare through the masks of the actor in the ancient theater), sent out by the organism, the "whole piece of art" termed "human being": a continuous process, visible for us with birth and seizing with death (there are two events an individual does not remember: birth and death). In this context the holistic approach teaches that the human being, including the physician, cannot be taken out of the context of the "whole", this continuous stream of energy. Some of this stream becomes perceivable to us, as it manifests itself as our world (Fig. 1). Semiotically the world consists of signs. Communication and reasoning work by the interpretation of signs. As a consequence semiotics demonstrate the wide and complex spectrum of being (Fig. 2). Now we are at turn to read the meaning of signs (meaning of being). Semiotics, the science of signs, has been initially introduced in the context of medicine. Describing the condi-

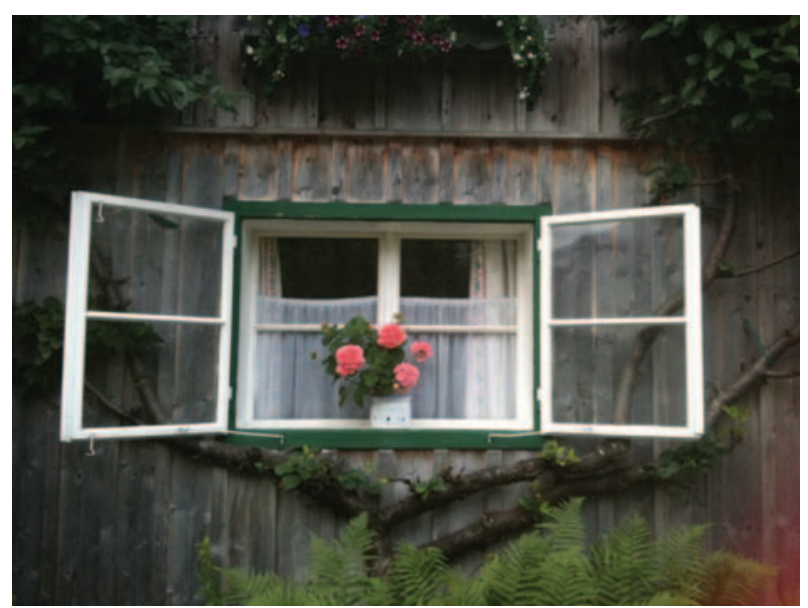

Fig. 1: Open your mind to perceive the positive signs of the world. Image taken by the author in Altaussee, Salzkammergut, Styria, Austria, using iPhone

Correspondence: Franz Martin Riegler, M.D., Associate Professor of Surgery, Manometry Lab \& Department of Surgery, Medical University Vienna, Währinger Gürtel 18-20, 1090 Vienna, Austria. Fax: ++43-1-40400 3478

E-mail: Franz.Riegler@meduniwien.ac.at

tion of a patient physicians listed anamnestic and diagnostic signs, which indicated in the prognostic signs.

The interpretation of a sign (Greek semios) is related to the cultural codes of an individual. Here Umberto Eco recently coined the term: "semiotic fields". Conceptually disease is a sign that indicates a disorder affecting the state of health, the life quality and the productivity of a person. The sense of the sign is to motivate a cascade of actions to eliminate the impairment of the life quality. Extrapolated to medicine the clinical sign is sent out of the patient and directed towards the physician to set the respective actions to treat the disease. Here disease serves as a sign to initiate the treatment.

In addition and most importantly, disease is a sign that harbors further fields of interpretation. Disease is a sign to indicate that it may affect everybody, even the

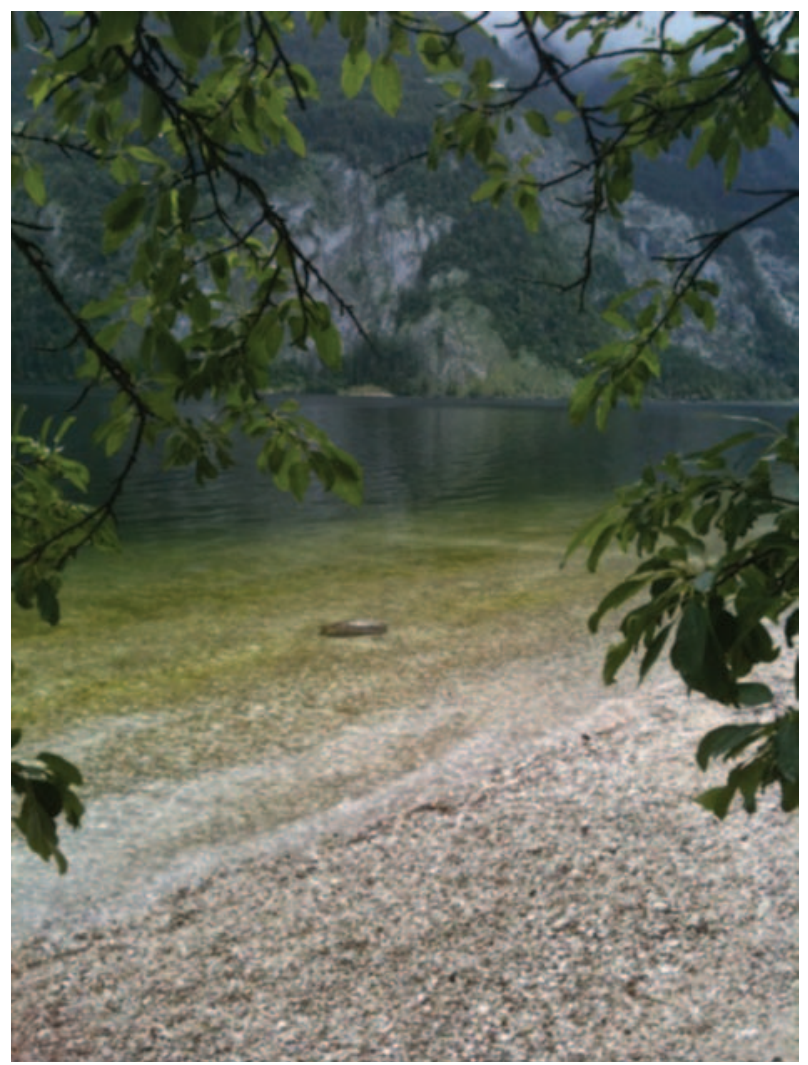

Fig. 2: The image indicates the spectrum of signs referring to the essence of life, the energy, which all perceivable sings have in common: energy. Image taken by the author in Altaussee, Salzkammergut, Styria, Austria, using iPhone 


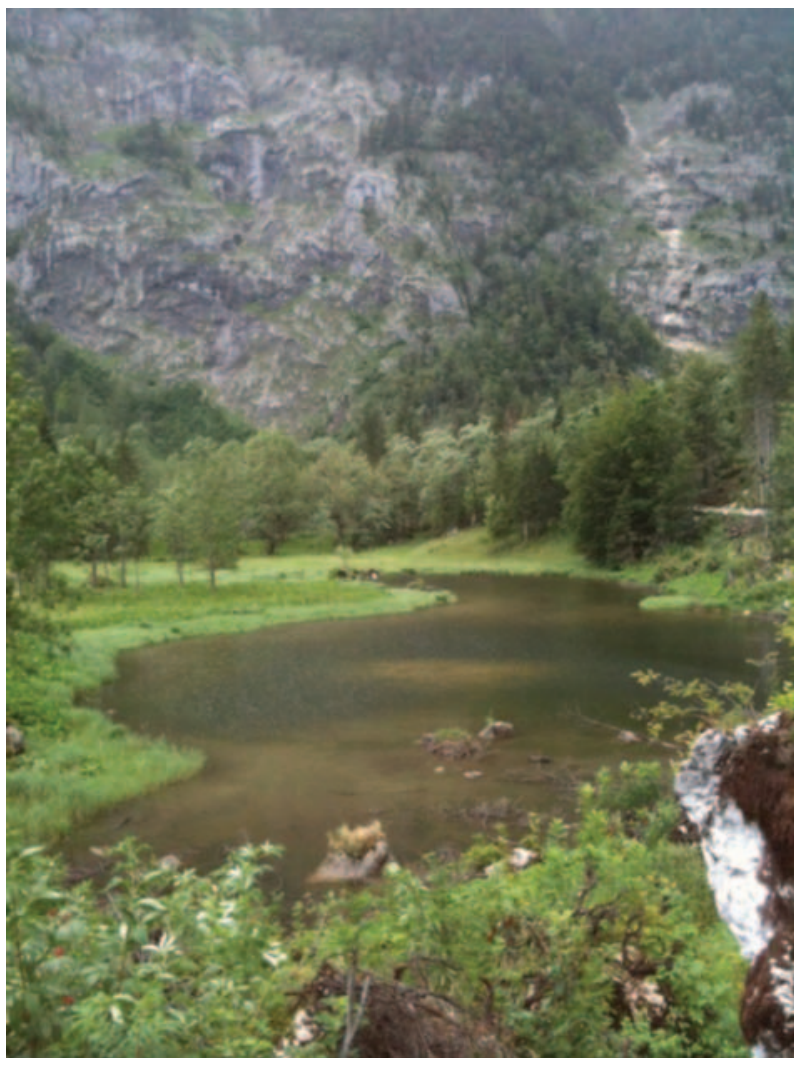

Fig. 3: Landscape contains a sign of highly positive energy. Image taken by the author in Altaussee, Salzkammergut, Styria, Austria, using iPhone

physician, who tends to exclude him/herself from this scenario. Thus disease tells us that we should be thankful for not having a disorder that impairs our health. Disease is perceived as a negative sign. But adequate interpretation of the sign may motivate positive energies: thankfulness, humility. In the same sense greediness and jealousy, the major "pathogens" of our present societies, are to be eliminated. Maybe that the distribution of these negative energies explains the increase of diseases which themselves are caused by greediness and jealousy: gastroesophageal reflux disease (GERD), obesity (over-eating, cannot get enough, got to get more than others) and diseases associated with these conditions (cardiac, respiratory, metabolic, auto-immune diseases, and malignomas). Thus disease may be interpreted as a sign telling us to change our way of life, to step back and reduce the speed, to leave more time for us, as individuals, and to give time to those who are important to us (family, friends, and patients). It seems that we cannot fully keep up with the "speedy" advantages of the present time (web-based communications). And most importantly, it is also true for us physicians.

As a physician we listen and learn from our patients whom to serve we are allowed: who feels it knows it and it could also be everyone of us who will become a patient one day (even today or tomorrow), having the same emotions, fears, and questions to be addressed. So we should be aware of that sign and stop to exclude us from the "whole". Since we physicians are exposed to diseases and patients every day, those signs also count for us.

Taken together, it is never too late for humility, thankfulness, and passion. It is never too late to eradicate the malignomas of our time: greediness, jealousy, and hate. You got to have love in your eyes to make a world for us and not against us. The "energy" is absolute, we decide on how to perceive it, positive or negative. Cheer up for positive vibrations, now and here: enjoy the colors of autumn and stay tuned (Fig. 3).

Franz Martin Riegler Editor in Chief

\section{Conflict of interest}

The author declares no conflict of interest. 